\title{
Ultra low concentration deltamethrin loaded patch development and evaluation of its repellency against dengue vector Aedes (S) albopictus
}

Pronobesh Chattopadhyay ${ }^{1}$, Sunil Dhiman ${ }^{2 *}$, Kangujam Adiya Devi ${ }^{3}$, Subham Banerjee$^{1}$, Bipul Rabha², Ashwani Chaurasia ${ }^{1}$ and Vijay Veer ${ }^{2}$

\begin{abstract}
Background: Mosquito repellents and emanators confer protection against mosquito bites through spatial action of emanated vapours which are released into the adjoining environment. Synthetic insecticides released into the environment in ultra low volume vapour phase deter the mosquitoes from biting humans in a protected space.

Methods: Formulation patches were prepared using the solvent evaporation method over a backing membrane and using Dibutylphthalate (DBT) as a plasticizer. The effect of formulation variables on the deltamethrin release from the patch matrices were studied under accelerated conditions, whereas, HPLC was used for quantitative estimation of deltamethrin. The prepared patch formulations were subjected to physicochemical studies, such as, deltamethrin content, thickness, weight variation, percent moisture content, moisture uptake, surface area and surface $\mathrm{pH}$ determination. Deltamethrin-polymer interaction and compatibility was ascertained using DSC and FT-IR, while surface morphology and deltamethrin distribution in the patch were studied using SEM technique. Repellent activity of the patch formulations was evaluated against Ae. albopictus mosquitoes.

Results: Blends of polymeric combinations of polyvinylpyrrolidone (PVP) and ethyl-cellulose (EC) with admixture of deltamethrin provided prolonged repellent activity against Ae. albopictus mosquitoes. Physicochemical characterisation indicated the suitability of deltamethrin patch formulation with the polymeric combinations of PVP and EC. Patches were very effective against laboratory reared Ae. albopictus mosquitoes. No significant difference was observed between the performance of test patches and commercially available repellent cream Mosqshield ${ }^{\varpi}$.

Conclusion: Deltamethrin loaded patches provided effective repellency against Ae. albopictus mosquitoes. The study emphasised that deltamethrin released to the environment in low concentration could be an excellent spatial repellent against hematophagous mosquitoes.
\end{abstract}

Keywords: Deltamethrin, Mosquito repellent, Patch, HPLC, Aedes (Stegomyia) albopictus

\footnotetext{
*Correspondence: sunildhiman81@gmail.com

${ }^{2}$ Division of Medical Entomology, Defence Research Laboratory, Tezpur 784 001,

Assam, India

Full list of author information is available at the end of the article
} 


\section{Background}

More than two billion people, mostly in tropical countries, are at risk of mosquito-borne diseases, such as malaria, dengue, Japanese encephalitis and filariasis $[1,2]$. Aedes (Stegomyia) albopictus (Diptera: Culicidae) is an epidemiologically important mosquito responsible for the transmission of many viral pathogens [2,3]. Ae. albopictus received considerable attention in India after recent reports indicating its potential role in disease transmission in various parts of the country [2,4-6]. Use of repellents as personal protection measures against the insect bites is the most accepted method to control insect vector borne diseases currently [7-9]. Many of the mosquito repellents, though available in the market and advertised to be effective repellents, are unpleasant and ineffective in repelling the mosquitoes [10]. However, an ideal mosquito repellent must provide a longterm protection and be effective against all mosquito species. The ideal repellent compound would prevent bites from a broad range of insect species, remain effective for a comparatively longer time, cause no irritation to skin or mucous membranes, possess no systemic toxicity, be totally greaseless and odourless and safe to all age groups including infants $[11,12]$. Repellents at a very low-dose may provide specific and low-toxicity augmentation to the conventional pesticides applied around houses and workplaces [13]. The most common mosquito repellent formulations available in the market containing DEET (N, N-diethyl-3-methylbenzamide), DEPA and deltamethrin have shown excellent repellency against mosquitoes and other biting insects [8,14-17]. Deltamethrin, first synthesized in 1974 and marketed in 1977, is considered to be a relatively safe synthetic mosquito repellent and widely used in tropical countries $[18,19]$. Deltamethrin is a synthetic pyrethroid insecticide which possesses an extremely high level of activity against a wide range of insects acting both by direct contact and ingestion [20]. Various synthetic chemicals used at toxic levels are currently the only confirmed effective strategy for mosquito vector control, but emerging insecticide resistance issues are threatening this approach [21]. Application of ultra low volume (ULV) insecticides has proved effective in managing high densities of adult vector mosquitoes [22].

The present study was designed to develop a suitable matrix type mosquito repellent patch containing deltamethrin using different blends of polymeric combinations for prolonged release of repellent against mosquitoes. This study presents a systematic approach of using deltamethrin in ultra low concentration as an effective repellent against Ae. albopictus mosquitoes and emphasises that use of ULV deltamethrin released into the environment could be an alternative method for controlling mosquitoes and other vector insects.

\section{Methods}

Deltamethrin was obtained as a gift sample from Tagros India Ltd. Mumbai, India. Polyvinylpyrrolidone (PVP K-30), Dibutylphthalate (DBT), and Ethylcellulose (EC, ethoxy content $48-49.5 \% \mathrm{w} / \mathrm{w}$ ) were obtained from Himedia Laboratories Pvt. Ltd. Mumbai, India. Chloroform and water (for HPLC) were obtained from Spectrochem Pvt. Ltd. Mumbai, India. Acetonitrile (for HPLC) was purchased from Merck Specialities Pvt. Ltd. Mumbai, India. Dimethylsulfoxide (DMSO) was purchased from Loba Cheime Pvt. Ltd. Mumbai, India. All reagents and solvents used were of analytical grade and used as received without any further purification.

\section{Preparation of deltamethrin loaded patches}

Deltamethrin loaded mosquito repellent patches were prepared by solvent evaporation method using varying ratios of different blends of polymers. DBT was used as plasticizer at a fixed concentration of $20 \% \mathrm{w} / \mathrm{w}$ of dry weight of polymer. Initially, the polymers at a varied ratio were dissolved in chloroform and then deltamethrin and plasticizer were added to it. This mixture was moulded into rings with defined surface area and thickness over the backing membrane on a horizontal surface followed by solvent evaporation at an ambient temperature. The rate of evaporation was controlled by inverting the funnel. The patches formed were separated from the rings for further processing.

\section{Physicochemical characterization of deltamethrin loaded patches \\ Physical appearance}

All the deltamethrin loaded patches were visually inspected for shape, smoothness, stickiness, clarity, homogeneity, flexibility and uniformity.

\section{Uniformity of weight}

Weight was determined by individually weighing three randomly selected patches from each batch of formulation. In the experiment, attention was given so that the individual weight was uniform as compared to the average weight. The weight was expressed by mean and standard deviation.

\section{Surface area}

Surface area of patches was studied by using a millimeter scale and expressed by mean and standard deviation.

\section{Surface $\mathrm{pH}$ determination}

The patches were allowed to remain in contact with chloroform for $2 \mathrm{~h}$ at room temperature, and $\mathrm{pH}$ was determined using $\mathrm{pH}$ paper. 


\section{Percent moisture uptake}

Weighed patches were kept in a dessicator at room temperature for $48 \mathrm{~h}$. These were exposed to $75.5 \%$ relative humidity over a saturated solution of aluminium chloride in a dessicator until a constant weight is achieved. The percent moisture uptake was calculated using the following formula;

$$
\begin{aligned}
\% \text { Moisture uptake }= & \text { Final weight-Initial weight } \\
& \times 100 / \text { Initial weight }
\end{aligned}
$$

\section{Percent moisture content}

Three patches from each formulation were weighed and kept in dessicators containing fused calcium chloride at $37^{\circ} \mathrm{C}$ until the notable weight change was observed. This weight was noted as the final weight. The percent moisture content is calculated using following formula;

$$
\begin{aligned}
\% \text { Moisture content }= & \text { Initial weight-Final weight } \\
& \times 100 / \text { Final weight }
\end{aligned}
$$

\section{Flatness}

A patch should possess a smooth surface and should not constrict with time. This can be demonstrated in a flatness study. For flatness determination, one patch is cut from the centre $(2 \times 1 \mathrm{~cm})$ and applied on the skin. The length of patch is measured and variation in length is measured by determining percent constriction. It is assumed that zero percent constriction refers to 100 percent flatness.

$$
\% \text { Constriction }=\mathrm{I}_{1}-\mathrm{I}_{2} \times 100 / \mathrm{I}_{1}
$$

Where, $\mathrm{I}_{2}=$ Final length of each strip, $\mathrm{I}_{1}=$ Initial length of each strip.

\section{Measurement of thickness}

The thickness of the patch was measured using a digital micrometer (Mitotousu, Tokyo, Japan) at three different points of each patch and was expressed in mean and standard deviation.

\section{Scanning electron microscopy (SEM)}

The surface morphology of the blank and deltamethrin loaded patches was studied using scanning electron microscopy (JEOL, JSM-6390 LV, England). The samples were mounted onto stubs using double sided adhesive tape and sputter coated with gold palladium. The coated patches were observed and photographed at the required magnification at room temperature.

\section{Estimation of deltamethrin by HPLC}

The estimation of the deltamethrin was performed using HPLC (Analytical technologies limited, Gujarat, India) with a UV/visible detector and $\mathrm{C}_{18}$ column (Chromosil, particle size $5 \mu \mathrm{m}, 250 \mathrm{~mm} \times 4.6 \mathrm{~mm}$ ). Deltamethrin was separated by isocratic elution technique with a mixture of mobile phase containing acetonitrile: water (80: 20,\% v/v) at a flow rate of $1.0 \mathrm{ml} / \mathrm{min}$ and $\mathrm{UV}$ detection at $245 \mathrm{~nm}$.

\section{Deltamethrin content}

The patch of specified diameter was extracted with chloroform and kept for about $2 \mathrm{~h}$ at room temperature in order to extract the deltamethrin completely from the polymeric matrix and centrifuged at $3000 \times g$ for 15 min. A fixed amount of resulting supernatant solution from above was analyzed for deltamethrin content using HPLC (Analytical technologies limited, Gujarat, India) as method described elsewhere [23].

\section{FT-IR spectrophotometry}

The infrared data are helpful to confirm the identity of the component and to detect the interaction of the components with the polymer. Infrared spectra of deltamethrin and polymer, alone and in physical mixtures were obtained and investigated for any possible interaction between polymer and deltamethrin by FT-IR spectrophotometer (Bruker, $\alpha$ Alpha-E, Germany).

\section{Differential scanning calorimetry (DSC)}

The physicochemical compatibility between the components and polymer used in the formulations of deltamethrin-loaded mosquito repellent patches were evaluated by DSC analysis. The DSC thermograms (Perkin Elmer, Jade DSC, USA) obtained for pure deltamethrin, pure polymers, their physical mixtures and formulated patches were compared to ascertain the interactions. Samples were heated at a temperature range between $50-250^{\circ} \mathrm{C}$ at a heating rate of $10^{\circ} \mathrm{C} / \mathrm{min}$.

\section{Release study}

The release study was carried out under accelerated conditions of higher temperature. Patches were kept in an oven at $40^{\circ} \mathrm{C}$ and withdrawn at different time intervals from each batch and then extracted with chloroform and kept for about $2 \mathrm{~h}$ at room temperature. The solution was centrifuged at $3000 \mathrm{rpm}$ for $15 \mathrm{~min}$ to remove the polymeric remnants and the supernatant liquid was collected and analyzed using HPLC.

\section{Mathematical modelling of release kinetics}

To understand the mechanism of deltamethrin permeation kinetics from the developed patches, the release data were fitted to various release kinetic equations;

Zero-order equation (cumulative percentage drug permeated vs. time) [24]

$$
Q_{t}=Q_{0}+k_{0 t}
$$


Where, $Q_{t}$ is the amount of deltamethrin release in time $t, Q_{o}$ is the initial amount of deltamethrin in the solution (most times, $Q_{0}=0$ ) and $k_{0}$ is the zero order release rate.

First-order equation (log cumulative percentage drug remaining to be permeated vs. time)

$$
\ln Q_{t}=\ln Q_{0}+k_{1} t
$$

Where, $Q_{t}$ is the amount of deltamethrin released in time $t, Q_{o}$ is the initial amount of deltamethrin in the solution and $\mathrm{k}_{1}$ is the first order release rate constant.

Higuchi's model equation

$$
Q=k_{H} t^{1 / 2}
$$

Where, $\mathrm{Q}$ is the amount of deltamethrin release at time $t$, and $k_{H}$ is the Higuchi diffusion rate constant.

Korsmeyer-peppas model [25]

$$
M t / M \alpha K t^{n}
$$

Where, $M t$ is the amount of deltamethrin released at time $t, M \alpha$ is the amount of deltamethrin released after infinite time, $K$ is a kinetic constant incorporating structural and geometric characteristics of the formulation and $n$ is the diffusional exponent indicative of the drug release mechanism.

\section{Mosquitoes and repellency test}

Ae. albopictus mosquitoes are regularly maintained in the laboratory under controlled temperature $\left(28 \pm 2^{\circ} \mathrm{C}\right)$ and relative humidity (75-80\%). For the present study, about 80-100 adult (3 days old) female Ae. albopictus mosquitoes were introduced into the customised repellent trial chamber $(46 \times 37 \times 36 \mathrm{~cm})$ through the hole on top with the help of sucking tube. Prior to testing, the mosquitoes were starved by providing them with only water for $12 \mathrm{~h}$. Both hands of the test volunteers were used for testing the repellent activity. The Right hand applied with a blank patch was the placebo control, while the left hand applied with a deltamethrin loaded patch was taken as the test. The repellent activity was evaluated by inserting the hand into the test chamber for one minute at the start of the trial $(0 \mathrm{~min})$, after $30 \mathrm{~min}$ interval for the first hour of application and after an interval of $60 \mathrm{~min}$ for the rest of testing duration. Therefore, mosquito landing and biting was recorded eleven times during each trial. The hand was placed inside the repellent chamber through a hole up to wrist and plugged with cotton to prevent escape of mosquitoes. The test chamber had clear glass sides and front (for viewing) and a sheet aluminium bottom. Sucrose solution $(10 \%)$ was available to the mosquitoes at all the times during the trial. Repellency was evaluated up to $9 \mathrm{~h}$ and the test mosquitoes were replaced with a new set of mosquitoes after $4 \mathrm{~h}$ of the trial. Commercially available DEPA (N, N-diethyl phenylacetamide) based mosquito repellent cream Mosqshield ${ }^{\circ}$, applied at $1.0 \mathrm{mg} / \mathrm{cm}^{2}$ was taken as positive control for comparison with the test patch. Each trial was replicated at least three times on different days using three volunteers. The volunteers were assigned randomly for each trial. All the volunteers selected were non smokers, non alcoholic and had no known history of allergic reactions to mosquito bites. The trials were randomised between the investigators in order to minimise the bias. Written informed consent was obtained from all volunteers used in the present study. Number of mosquitoes attempted to settle for the blood feed were scored as landing, whereas those landed successfully and attempted to suck blood were scored as biting.

The percent repellency was calculated using equation -5

$$
\text { Percentrepellency }(\mathrm{PR})=\mathrm{C}-\mathrm{N} \times 100 / \mathrm{C}
$$

Where, $\mathrm{C}=$ Number of mosquitoes on control $\mathrm{N}=$ Number of mosquitoes on test

The repellency index was calculated using the equation -6

$$
\text { Repellency index }(\mathrm{RI})=(\mathrm{C}-\mathrm{N} \times 100) /(\mathrm{C}+\mathrm{N})
$$

\section{Data analysis}

The values obtained in the physiochemical characterisation were expressed as mean \pm standard deviations. PR and RI obtained at different time intervals of the trials were compared using two-way ANOVA followed by Tukey-Krammer test of multiple comparisons at 95\% confidence interval. Further, the PR and RI of deltamethrin loaded patch (test) and Mosqshield ${ }^{\circ}$ cream (positive control) at different time intervals of test were compared using Student's ' $t$ ' test.

The study project was approved by the Institutional Review Committee of Defence Research Laboratory, Tezpur and Ethical Review Committee of LGB Regional Institute of Mental Health, Tezpur. Informed written consents were obtained from the volunteers participated in the repellent trials.

\section{Results}

\section{Physiochemical characteristics}

The physicochemical characteristics of the deltamethrinloaded mosquito repellent patches along with different combinations of EC and PVP have been presented in Table 1. The weight variation and the surface area of all the formulations varied from $0.46 \pm 0.10$ to $0.54 \pm 0.06$ and $13.64 \pm 1.37$ to $14.51 \pm 0.68$ respectively. The moisture uptake ranged from $3.42 \pm 2.66$ to $8.92 \pm 5.79$, while the moisture content was $2.60 \pm 0.25$ to $5.52 \pm 0.43$. The prepared patches were found to be uniform in thickness 
Table 1 Composition and physicochemical characterization of deltamethrin-loaded mosquito repellent patches

\begin{tabular}{cccccccc}
\hline $\begin{array}{c}\text { Formulation } \\
\text { batch }\end{array}$ & $\begin{array}{c}\text { EC: PVP-K } \\
\mathbf{3 0}\end{array}$ & $\begin{array}{c}\text { Weight variation } \\
\mathbf{( g m})\end{array}$ & $\begin{array}{c}\text { Thickness } \\
(\mathbf{m m})\end{array}$ & $\begin{array}{c}\text { Surface area } \\
\left(\mathbf{c m}^{\mathbf{2}}\right)\end{array}$ & $\begin{array}{c}\text { Moisture uptake } \\
\mathbf{( \% )}\end{array}$ & $\begin{array}{c}\text { Moisture content } \\
(\mathbf{\%})\end{array}$ & $\begin{array}{c}\text { Deltamethrin } \\
\text { content }\end{array}$ \\
\hline A1 & $1: 2$ & $0.47 \pm 0.07$ & $0.42 \pm 0.03$ & $14.51 \pm 0.68$ & $7.31 \pm 4.33$ & $4.50 \pm 0.60$ & 50.35 \\
A2 & $2: 1$ & $0.48 \pm 0.06$ & $0.41 \pm 0.01$ & $13.84 \pm 0.66$ & $4.67 \pm 2.66$ & $3.13 \pm 0.10$ & 75.76 \\
A3 & $3: 0$ & $0.46 \pm 0.10$ & $0.51 \pm 0.01$ & $14.30 \pm 1.41$ & $3.42 \pm 2.66$ & $2.60 \pm 0.25$ & 77.60 \\
A4 & $0: 3$ & $0.54 \pm 0.06$ & $0.57 \pm 0.01$ & $14.09 \pm 1.68$ & $8.92 \pm 5.79$ & $5.52 \pm 0.43$ & 62.05 \\
A5 & $1.5: 1.5$ & $0.46 \pm 0.04$ & $0.35 \pm 0.01$ & $13.64 \pm 1.37$ & $6.23 \pm 1.57$ & $3.18 \pm 0.11$ & 66.41 \\
\hline
\end{tabular}

and variation in the thickness of all the formulations were in the range of $0.35 \pm 0.01$ to $0.57 \pm 0.01$. Thickness uniformity and low weight variation indicated the uniformity in the patches. The values of all the physicochemical parameters evaluated were in the appropriate range. The percent deltamethrin content was found to ranged from 50.35 to $77.60 \%$ among all the patches. The surface $\mathrm{pH}$ of the patches was $\sim 6$ which is similar to human skin $\mathrm{pH}$, indicating that these patches were nonirritating to the skin. The kinetic study revealed that A5 bath formulation was best optimized and displayed Fickian diffusion controlled release mechanism governed by Higuchi kinetics (Table 1).

\section{SEM analysis}

SEM photographs demonstrate the homogeneous dispersion of deltamethrin in the polymeric matrices. The developed patches were spherical, smooth, less sticky, clear, homogenous and uniform as confirmed by SEM study (Figure 1a and b).

\section{FT-IR analysis}

The FT-IR spectra of deltamethrin showed peaks, at $1732.85 \mathrm{~cm}^{-1}$ due to carbonyl compound, at $1486.35 \mathrm{~cm}^{-1}$ for ring stretch absorption $\mathrm{C}=\mathrm{C}$ groups, at $1118.74 . \mathrm{cm}^{-1}$ due to aromatic $\mathrm{C}-\mathrm{O}-\mathrm{C}$ stretch, at $1013.85 \mathrm{~cm}^{-1}$ due to aromatic ethers of $\mathrm{C}-\mathrm{O}$ band groups, at $749.60 \mathrm{~cm}^{-1}$ showed out of plane bending due to $=\mathrm{C}-\mathrm{H}$ group and at $643.22 \mathrm{~cm}^{-1}$ due to strong stretch in aliphatic bromides (Figure 2a). In the deltamethrin loaded patch, the spectra of EC showed peaks at $3474.74 \mathrm{~cm}^{-1}$ due to O-H group, at $2973.06 \mathrm{~cm}^{-1}$ symmetric stretch due to the presence of $\mathrm{C}-\mathrm{H}$ group, at $1481.98 \mathrm{CH}_{2}$ bending and at $1374.66 \mathrm{~cm}^{-1}$ due to $\mathrm{CH}_{3}$ bending, while for PVP, the spectra showed peak at $3423.30 \mathrm{~cm}^{-1}$ due to amide $\mathrm{N}-\mathrm{H}$ stretching, at $1644.92 \mathrm{~cm}^{-1}$ due to $\mathrm{C}=\mathrm{O}$ group and at $1457.93 \mathrm{~cm}^{-1}$ due to methylene group bending absorption (Figure 2b). However, similar characteristic peaks related to deltamethrin were noticed with slight variations in deltamethrin loaded patches. Results suggested that the deltamethrin was stable in the patch formulation.

\section{DSC analysis}

DSC analysis of deltamethrin showed a sharp endothermic peak at $107.85^{\circ} \mathrm{C}$ corresponding to its melting point (Figure 3a). Whereas, the deltamethrin loaded patch with EC: PVP showed a blunt endothermic peak at $119.88^{\circ} \mathrm{C}$ with slight change in melting point of deltamethrin towards higher temperature (Figure $3 \mathrm{~b}$ ). DSC results indicated that the formulation did not show any physical transformation and was stable.
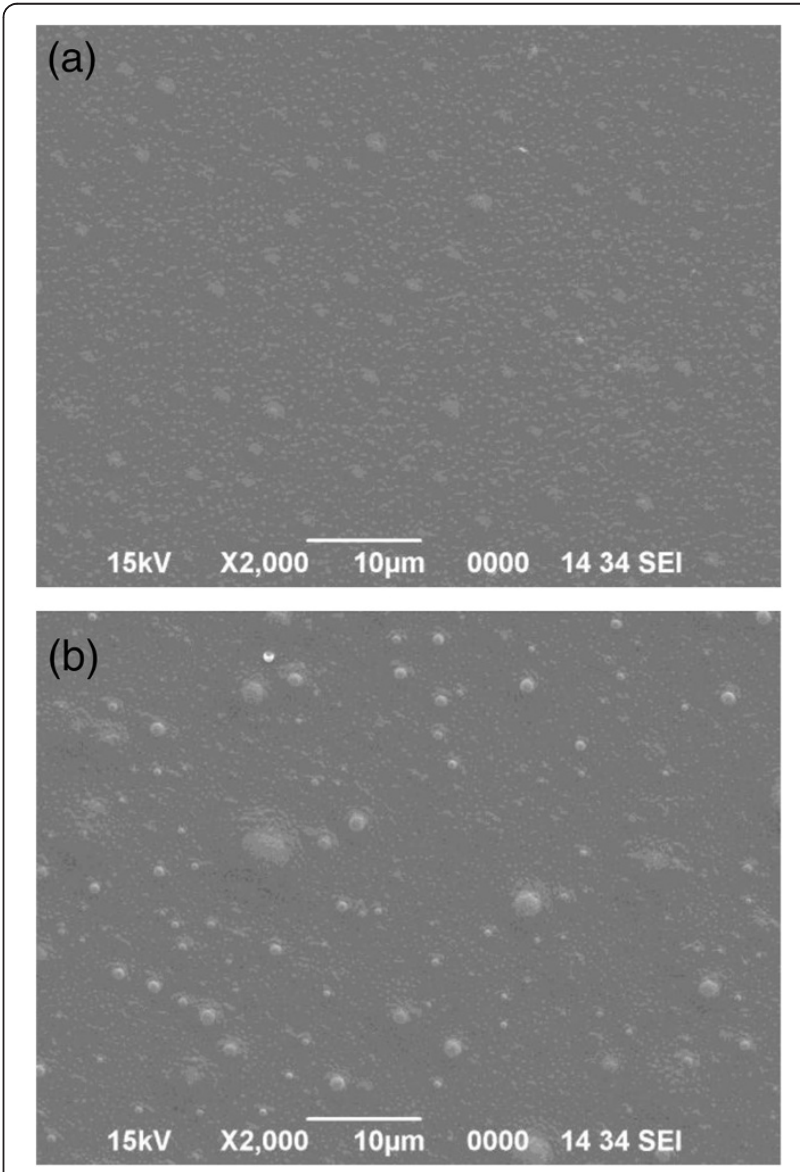

Figure 1 SEM microphotograph. Microphotograph of scanning electron microscope (SEM) showing the homogeneous dispersion of the deltamethrin in the polymeric matrices (a) blank patch (b) deltamethrin loaded patch ( $\times 2000)$. 
(a)

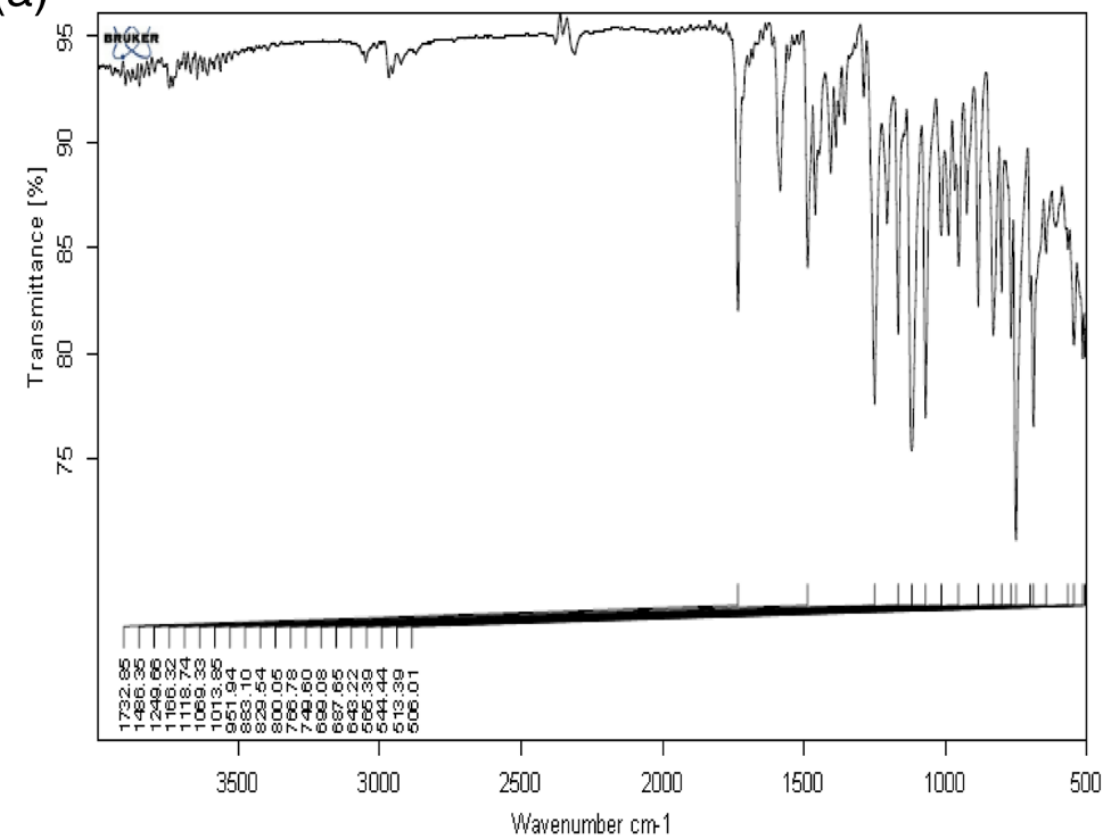

(b)

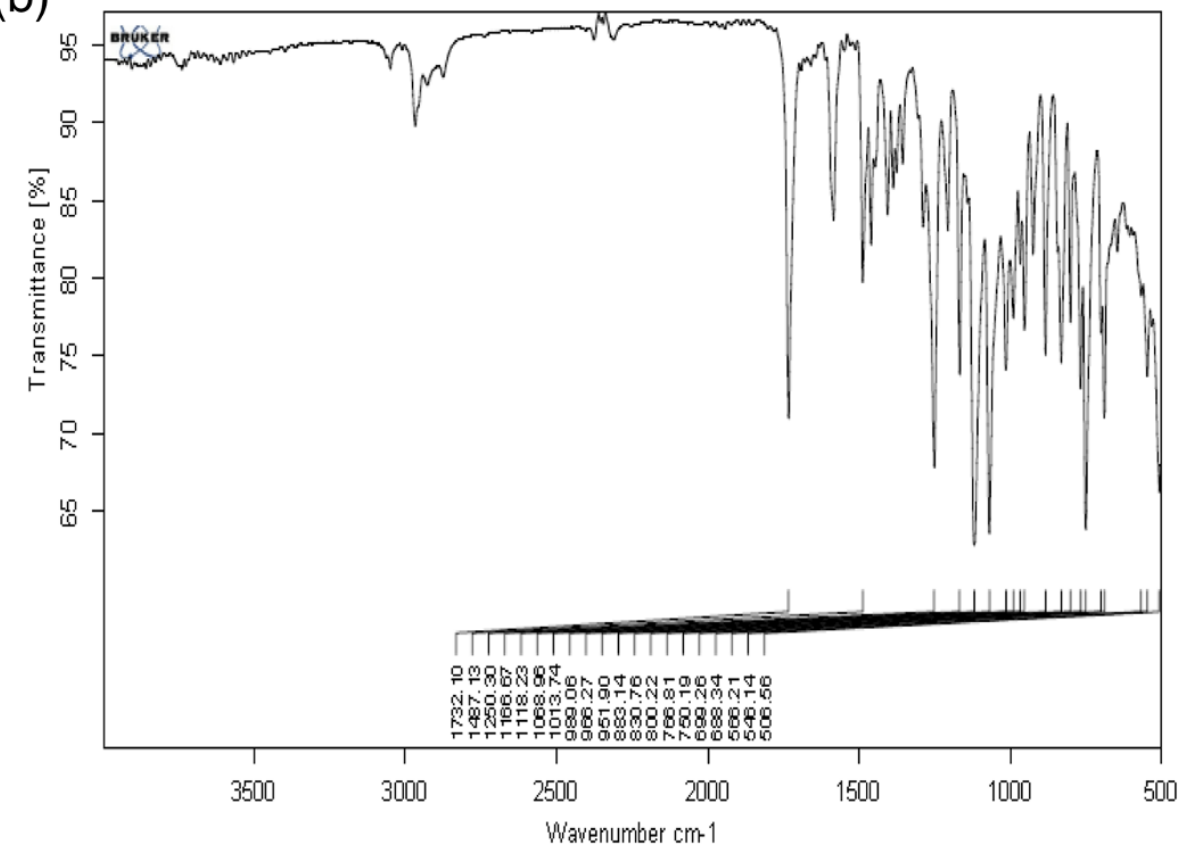

Figure 2 FT-IR microphotograph. Microphotograph of FT-IR spectroscopy (a) deltamethrin (b) deltamethrin loaded patch.

\section{Repellency evaluation}

Repellent activity of the deltamethrin-loaded patches was evaluated up to $9 \mathrm{~h}$ and comparisons were made with DEPA based commercial mosquito repellent cream Mosqshield ${ }^{\oplus}$ under laboratory conditions. Randomly selected patches from all the batches did not show a significant difference in the repellent activity (Table 1). Test patches displayed a consistent landing repellency throughout the trials, as both $\mathrm{PR}(\mathrm{F}=1.64 ; \mathrm{p}=0.17)$ and RI $(\mathrm{F}=1.69 ; \mathrm{p}=0.15)$ did not differ statistically at various time intervals. The comparison of the landing repellency of test patch and Mosqshield ${ }^{\ominus}$ cream has been shown in Figure 4a and b. At the beginning of the trial, the PR and RI of test patch were 90.9 and 83.3 respectively, while in Mosqshield ${ }^{\odot}$ cream both PR and RI were 100 each. However, after $9 \mathrm{~h}$ of the application, the 
(a)

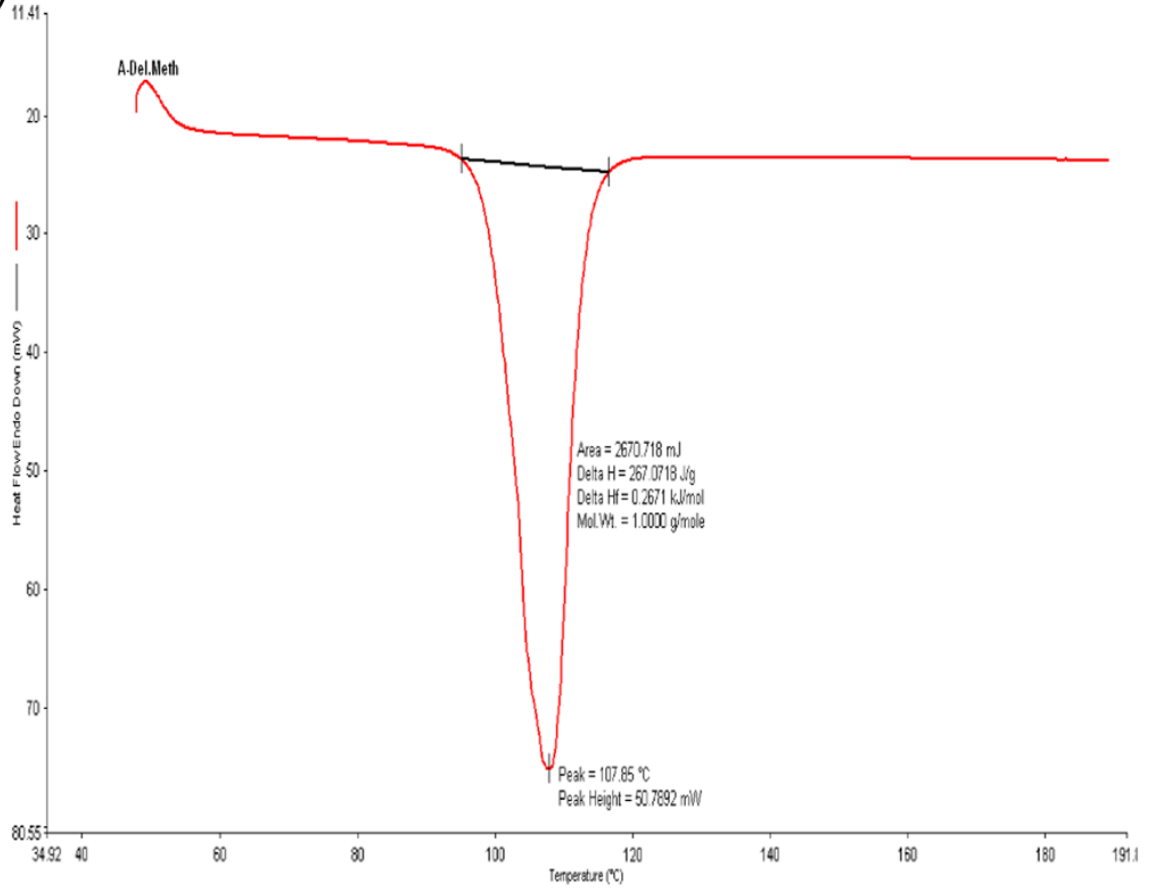

(b)

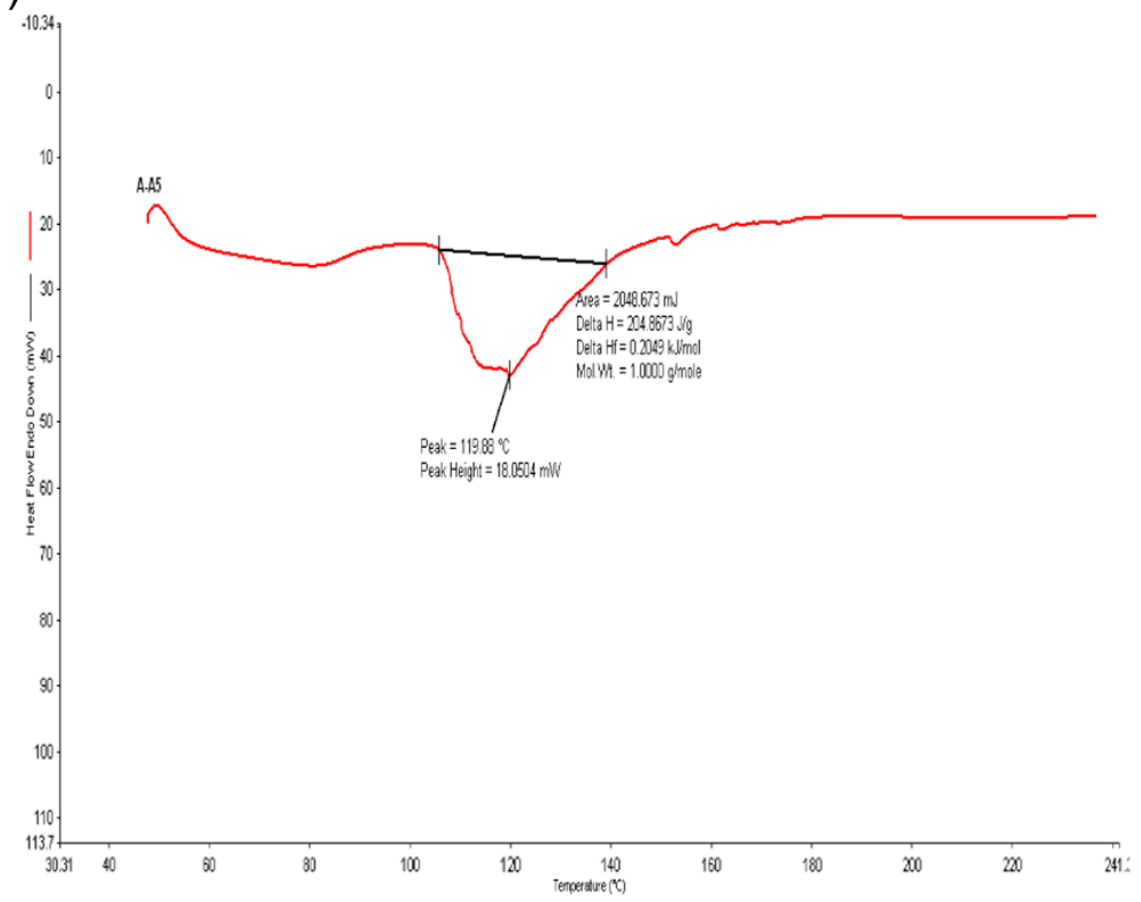

Figure 3 DSC phase diagram. Phase diagram of differential scanning calorimeter (DSC) (a) deltamethrin (b) deltamethrin loaded patch.

landing PR and RI of test patch decreased to 68.2 and 51.2, while in Mosqshield ${ }^{\circ}$ it decreased to 77.3 and 62.9 respectively. No statistical difference was observed among the landing PR and RI of test patch and Mosqshield ${ }^{\circ}$ cream at various time intervals $(t \geq 1.99 ; \mathrm{p} \geq 0.19)$. Biting repellency of test patches as compared to Mosqshield ${ }^{\circ}$ has been depicted in Figure 5a and b. There was no significant difference among the biting PR $(F=0.34 ; \mathrm{p}=0.96)$ and $\mathrm{RI}$ $(\mathrm{F}=0.37 ; \mathrm{p}=0.94)$ at various testing time intervals. The biting repellency of test patches and Mosqshield $^{\bullet}$ was 

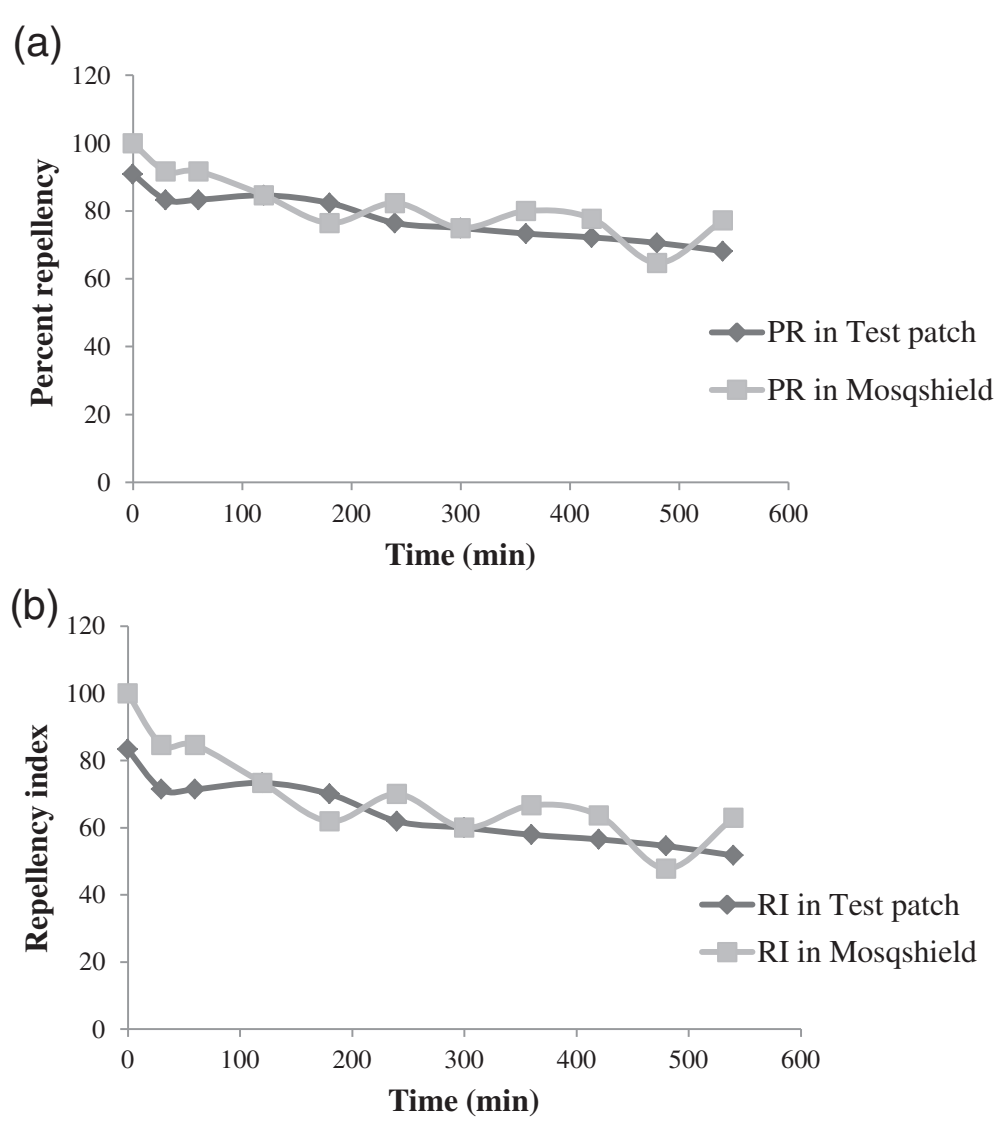

Figure 4 Landing protection against Ae. albopictus. Landing repellency of deltamethrin loaded patch and Mosqshield ${ }^{\circledR}$ against Ae. albopictus (a) percent repellency $(\mathbf{b})$ repellency index.

found to be statistically similar, as there was no difference among the PR $(\mathrm{t} \geq 1.21 ; \mathrm{p} \geq 0.29)$ and $\mathrm{RI}(\mathrm{t} \geq 1.18 ; \mathrm{p} \geq 0.31)$ of test patch and Mosqshield ${ }^{\circ}$ at various time intervals during the test.

\section{Discussion}

Although the variety of mosquito repellents available now a days is remarkable, still the use of ULV insecticides remains a popular option for controlling the mosquitoes. In the present investigation, for the first time we showed that the use of ULV deltamethrin in a polymer patch is effective as repellent against laboratory reared Ae. albopictus mosquitoes. Ae. aegypti and Ae. albopictus are well known vectors responsible for the transmission of dengue fever in many countries $[2,3,26]$. The emergency interventions in dengue outbreaks rely on the indoor thermal fogging and outdoor ULV application of suitable insecticides [21,27]. While effective, these interventions are difficult to implement and sustain in the urban settings, where Ae aegypti is more common and potential dengue vector $[21,28]$. Global climate change has led to the range expansion of mosquito species and resistance to the insecticides, therefore, limited exposure of insecticide is recommended in antimosquito efforts.

Some of the commercially available formulations may contain up to $40 \%$ synthetic insecticide and claim that the higher concentrations are most appropriate to use when, mosquito biting pressure and the risk of mosquito borne diseases is high and the environmental conditions promote rapid loss of repellent $[29,30]$. The deltamethrin patch formulation developed in the present study has minimal insecticide exposure for humans, thereby reducing the human-health and environment related risks. The moisture content $(2.60 \pm 0.25$ to $5.52 \pm 0.43)$ of these patches was consistent with the increasing hydrophilic polymer (PVP) content, while the moisture uptake varied from $3.42 \pm 2.66$ to $8.92 \pm 5.79$. The variation occurred due to the presence of different ratios of polymers. High moisture uptake corresponds to the use of high concentrations of PVPK-30, which is hydrophilic and hygroscopic in nature. Low moisture uptake capacity has the advantage that it protects the patches from microbial contamination and bulkiness during high humid conditions. There was no difference in the length of the strips before and after cutting in longitudinal 

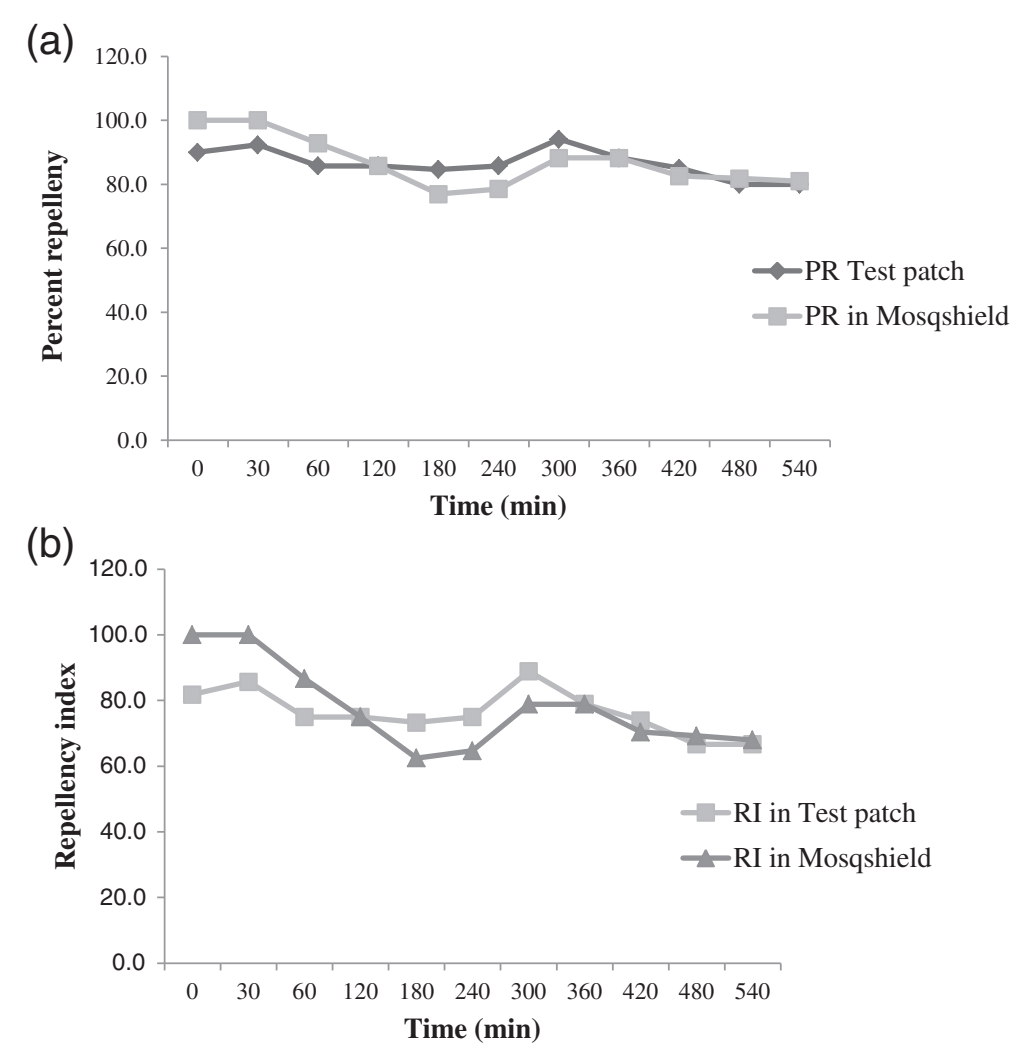

Figure 5 Biting protection against Ae. albopictus. Biting repellency of deltamethrin loaded patch and Mosqshield ${ }^{\circledR}$ against Ae. albopictus (a) percent repellency (b) repellency index.

sections, indicating zero constriction and 100\% flatness. Therefore, the patches maintained a smooth and uniform surface when applied on the human hand for evaluating the anti-mosquito efficacy. The FT-IR and DSC studies indicated compatibility between deltamethrin and the excipients used in the fabrication of the repellent patches.

Many of the synthetic repellent based products have not been proved to be efficacious in mosquito control [10]. However, some studies have suggested that synthetic insecticide based products are highly effective in repelling the mosquitoes and other hematophagous insects $[8,16,30,31]$. The synthetic insecticides have been found to be consistent in activity even after a long period of use, unlike the herbal based repellents, which provide repellency initially but after some time the activity ceases $[7,9,16,32]$. Other studies have indicated that many of the synthetic repellents while applied along with the other repellents provide more protection against mosquitoes as compared to applied singly [33]. The repellent patches developed and evaluated in the present study were assumed to provide protection against the mosquito up to 3-4 h only, but these patches were effective even after 8-9 h of the application and compared well with the commercial formulation Mosqshield ${ }^{\circ}$. These patches would have selective advantages over the cream and lotion based synthetic formulations. The cream and lotion based repellent formulations are comparatively less preferred because these are applied directly onto the bare skin and sometime causes discomfort to the user.

The deltamethrin loaded patches developed here were proven to be safe to the user and effective against mosquitoes. The patch is completely safe because the backing material used in the formulation acts as barrier for deltamethrin to penetrate into the human skin. The active component is slowly released into the surrounding atmosphere at a very low concentration. The patches were found to be stable and displayed very good physical properties at room temperature. The repellent patch formulation is a novel approach and provides alternate mechanism to deliver deltamethrin into the surrounding environment effectively. Present results could be helpful in developing specific uses such as providing mosquito repellents which would be useful during outdoor working hours.

\section{Conclusion}

Deltamethrin loaded patches developed in the present study provided promising results in repelling the $A e$. albopictus mosquitoes under laboratory conditions. The study emphasised that deltamethrin released to the 
environment at ultra low concentration could be a useful method for providing protection against mosquitoes in the tropical settings. However, the present findings relate to the application of the repellent patches against laboratory reared Ae. albopictus mosquitoes only, therefore, more detailed, multicentric and well replicated field studies are essential to establish long-term efficacy, practicability, affordability and acceptability of the developed patches against a variety of vector mosquitoes.

\section{Competing interests}

The authors declare that they have no competing interests.

\section{Authors' contributions}

All the authors have contributed significantly to this study. PC, SD and W conceptualized and designed the study. SB, KAD, AC and PC performed the analytical studies. SD and PC performed data analysis. BR, SD and KAD performed the repellency experiments. PC and SD prepared the manuscript. W critically reviewed the manuscript. The opinions contained herein are the personal views of the authors only and are not to be considered as official views of the Department of Defence R\&D, Govt of India. Mention of specific commercial products is for better understanding and does not constitute any recommendation. All authors read and approved the final manuscript.

\section{Acknowledgement}

We acknowledge the support of the Defence Research Laboratory (DRL), Defence R \& D Organization (DRDO), Ministry of Defence, Govt. of India, Tezpur, Assam (India).

\section{Author details}

'Division of Pharmaceutical Technology, Defence Research Laboratory, Tezpur 784 001, Assam, India. ${ }^{2}$ Division of Medical Entomology, Defence Research Laboratory, Tezpur 784 001, Assam, India. ${ }^{3}$ Department of Pharmaceutics, Girijananda Chowdhury Institute of Pharmaceutical Science, Guwahati 781017, Assam, India.

Received: 23 July 2013 Accepted: 24 September 2013 Published: 28 September 2013

\section{References}

1. Service MW: Mosquitoes (Culicidae). In Medical insects and arachnids. Edited by Lane RP, Crosskey RW. London: Chapman and Hall; 1993:723.

2. Rezza G: Aedes albopictus and the reemergence of dengue. BMC Pub Health 2012, 12:72.

3. Guillaumot L, Ofanoa R, Swillen L, Singh N, Bossin HC, Schaffner F: Distribution of Aedes albopictus (Diptera, Culicidae) in southwestern Pacific countries, with a first report from the Kingdom of Tonga. Parasites \& Vectors 2012, 5:247.

4. Tewari SC, Thenmozhi V, Katholi CR, Manavalan R, Munirathinam A, Gajanana A: Dengue vector prevalence and virus infection in a rural area in south India. Trop Med Int Health 2004, 9(4):499-507.

5. Dutta P, Khan SA, Khan AM, Borah J, Chowdhury P, Mahanta J: First evidence of chikungunya virus infection in Assam, Northeast, India. Trans R Soc Trop Med Hyg 2011, 105:355-357.

6. Banerjee S, Aditya G, Saha GK: Pupal productivity of dengue vectors in Kolkata, India: implications for vector management. Indian J Med Res 2013, 137(3):549-559.

7. Kweka EJ, Munga S, Mahande AM, Msangi S, Mazigo HD, Adrias AQ, Matias $J R$ : Protective efficacy of menthol propylene glycol carbonate compared to N: N-diethyl-methylbenzamide against mosquito bites in Northern Tanzania. Parasites \& Vectors 2012, 5:189.

8. Kalyanasundaram M, Mathew N: N, N-diethyl phenylacetamide (DEPA): a safe and effective repellent for personal protection against hematophagous arthropods. J Med Entomol 2006, 43(3):518-525.

9. Hazarika S, Dhiman S, Rabha B, Bhola RK, Singh L: Repellent activity of some essential oils against Simulium species in India. J Insect Sci 2012, 12:5.

10. Revay EE, Junnila A, Xue RD, Kline DL, Bernier UR, Kravchenko VD, Qualls WA, Ghattas N, Muller GC: Evaluation of commercial products for personal protection against mosquitoes. Acta Trop 2013, 125(2):226-230.
11. Fradin MS: Mosquitoes and mosquito repellents-a clinician's guide. Ann Intern Med 1998, 128:931-940.

12. Katritzky AR, Wang Z, Slavov S, Dobchev DA, Hall CD, Tsikolia M, Bernier UR, Elejalde NM, Clark GG, Linthicum JK: Novel carboxamides as potential mosquito repellents. J Med Entomol 2010, 47(5):924-938.

13. Peterson C: Insect repellents in urban settings. Biologist 2003, 50:39-43.

14. Yap HH, Jahangir K, Chong ASC, Adanan CR, Chong NL, Malik YA, Rohaizat B: Field efficacy of a new repellent, KBR 3023, against Aedes (S.) albopictus and Culex quinquefasciatus in a tropical environment. J Vector Ecol 1998, 23:62-68.

15. Walker TW, Robert LL, Copeland A, Githeko AK, Wirtz RA, Githure Jl, Klein TA: Field evaluation of arthropod repellents, deet and a piperidine compound, Al3-37220, against Anopheles funestus and Anopheles arabiensis in West Kenya. J Am Mosa Control Assoc 1996, 12:172-176.

16. Maia MF, Abonuusum A, Lorenz LM, Clausen PH, Bauer B, Garms R, Kruppa T: The effect of deltamethrin-treated net fencing around cattle enclosures on outdoor-biting mosquitoes in Kumasi, Ghana. PLoS One 2012, 7(9):e45794.

17. Ogoma SB, Ngonyani H, Simfukwe ET, Mseka A, Moore J, Killeen GF: Spatial repellency of transfluthrin-treated hessian strips against laboratoryreared Anopheles arabiensis mosquitoes in a semi-field tunnel cage. Parasit Vectors 2012, 5:54

18. Abdel-Khalik MM, Hanafy MS, Abdel-Aziz MI: Studies on the teratogenic effects of deltamethrin in rats. Dtsch Tierarztl Wochenschr 1993, 100(4):142-143.

19. Zaim M, Aitio A, Nakashiman N: Safety of pyrethroid-treated mosquito nets. Med Vet Entomol 2000, 14:1-5.

20. Worthing CR, Walker R: The pesticide manual-a world compendium. Thornton Heath, British Crop Protection Council 1987, 8:395-396.

21. Manda H, Shah P, Polosomboon S, Chareonviriyaphap T, Lianos FA, Burrus RG, Grieco JP, Achee NL: Contact irritant responses of Aedes aegypti using sublethal concentration and focal application of pyrethroid chemicals. PLoS Negl Trop Dis 2013, 7:e2074.

22. Schleier JJ III, Peterson RK, Irvine KM, Marshall LM, Weaver DK, Preftakes CJ: Environmental fate model for ultra-low-volume insecticide applications used for adult mosquito management. Sci Total Environ 2012, 438:72-79.

23. Tyagi A, Sharma M, Singh K, Fatima K, Rawat VS, Aggarwal M, Khandal RK: Studies on deltamethrin treated mosquito net. E-J Chem 2010, 7:S15-S22.

24. Wyatt DA: Taking poorly water soluble compounds through discovery, in: recent advances in the formulations and development of poorly soluble drugs. Bull Tech Gattefosse 1999, 92:31-39.

25. Korsmeyer RW, Gurny R, Doelker E, Buri P, Peppas NA: Mechanisms of solute release from porous hydrophilic polymers. Int J Pharm 1983, 15:25-35.

26. Dutta P, Mahanta J: Potential vectors of dengue and the profile of dengue in the north eastern region of India: an epidemiological perspective. Dengue Bull 2006, 30:234-242.

27. Erlanger TE, Keiser J, Utzinger J: Effect of dengue vector control interventions on entomological parameters in developing countries: a systematic review and meta-analysis. Med Vet Entomol 2008, 22:203-221.

28. Morrison AC, Zielinski-Gutierrez E, Scott TW, Rosemberg R: Defining challenges and proposing solutions for control of the virus vector Aedes aegypti. PLoS Med 2008, 5:e68.

29. Gupta RK, Rutledge LC: Laboratory evaluation of controlled-release repellent formulations on human volunteers under three climatic regimens. J Am Mosa Control Assoc 1989, 5:52-55.

30. Fradin MS, Day JF: Comparative efficacy of insect repellents against mosquito bites. N Engl J Med 2002, 347(1):13-18.

31. Trongtokit $Y$, Curtis CF, Rongsriyam Y: Efficacy of repellent products against caged and free flying Anopheles stephensi mosquitoes. Southeast Asian J Trop Med Pub Health 2005, 36:1423-1431.

32. Dhiman S, Rabha B, Chattopadhyay P, Das NG, Hazarika S, Bhola RK, Veer V, Singh $L$ : Field evaluation of repellency of a polyherbal essential oil against blackflies and its dermal toxicity using rat model. Trop Biomed 2012, 29(3):391-397.

33. Bhatnagar A, Mehta VK: Efficacy of deltamethrin and cyfluthrin impregnated cloth over uniform against mosquito bites. Med J Armed Forces India 2007, 63:120-122.

doi:10.1186/1756-3305-6-284

Cite this article as: Chattopadhyay et al.: Ultra low concentration deltamethrin loaded patch development and evaluation of its repellency against dengue vector Aedes (S) albopictus. Parasites \& Vectors $20136: 284$ 